Original Article

\title{
Acne vulgaris leading to psychosocial problems among youth of Karachi
}

\section{Shadab Batool, Sumera Sohail, Ghazala Yasmeen, Nazish Iqbal, Lubna Naz \& Mufzala Shamim}

Department of Physiology, University of Karachi.
DOI:10.29052/IJEHSR.v7.i2.2019.93-100

Corresponding Author Email:

sumera_sohail@yahoo.com

Received 07/12/2018

Accepted 26/03/2019

Published 01/06/2019

\section{(c) (i)}

(c) The Author(s). 2019 Open Access This article is distributed under the terms of the Creative Commons Attribution 4.0 International License (http://creativecommons.org/licenses/by/4.0/)

\section{Abstract}

Background: Acne Vulgaris (AV) is one of the most common prevalent dermal condition and is testified to have affected $80 \%$ of the world's populace around the vividly marked ages of 13 to 30 years. The current study is designed to investigate the association among acne and multifactorial pathogenesis along with social factors and psychological impacts on effected individuals.

Methodology: A survey-based study on a sample of 500 subjects was conducted from February 2016 to October 2016. A structured questionnaire classified into different sections concerning the demographic characteristics, skin type, complexion were inquired while the lifestyle factors like smoking, drinking habits and other factors leading to AV or associated stress were also interrogated.

Results: According to the study results AV was found to be more prevalent in both sexes with a slightly increased outbreak in males $(52.4 \%)$ as compared to females $(47.6 \%)$. There was no significant relationship observed between the breakout places of AV and its impact on self-confidence $(p=0.197)$ whereas its impact on the subject's social involvement was significant $(\mathrm{p}<0.00 \mathrm{I})$. Skin type was also found significantly associated with AV outbreak $(\mathrm{p}<0.05)$. Apart from physiological factors, smoking was also one of the triggers for AV $(p<0.05)$ while Stress was also correlated with acne and its severity $(p<0.000)$.

Conclusion: Despite being the most prevalent common dermal condition, AV and its associated psychological impacts had been neglected worldwide. This under-rated public health concern leads to a number of psychosocial problems leading to diminished confidence, self-esteem, rejections and even suicidal thoughts among those affected with it.

\section{Keywords}

Sebum Accretion, Sebaceous Follicles, Propionibacterium Acne, Acne Vulgaris. 


\section{Introduction}

Despite being the most prevalent distressing condition common among youth, AV has negative impact on the mental health of the affectees ${ }^{1-6}$ It is characterized by the dead skin cells and sebum accretion, augmenting the microbial load within the sebaceous follicles, disrupting the follicular wall and thus instigating inflammation of the dermis ${ }^{7}$. Even though the ailment not being claimed to be life menacing, but it is a very severe psychological adverse encumbrance on individuals of all race, as acne breaks out and spreads to the chest, back and predominantly face, the motive of humiliation for the mainstream of the sufferers ${ }^{8}$. Due to which there are personality progression glitches specifically in young individuals who are just undergoing character edification'. Almost every teenage girl or boy suffers from $A V$, it is reported that $65-75 \%$ population complain regarding this distressing issue ${ }^{10}$. Individuals with AV experience more anxiety and social withdrawal as compared to non-sufferers of $\mathrm{AV}^{\mathrm{II}}$.

AV is manifested through various features which are mainly dependent on the severity of the disease ${ }^{12}$. The classified morphologies include comedones (whiteheads), open comedones (blackheads), deep pustules or pseudocysts, erythematous papules, cysts (nodules), seborrhea and ultimately scarring in the pustules ${ }^{\mathrm{I} 2}$. Its pathological exhibition can range from a mild comedonal form to severe inflammatory cystic acne of the back, chest and the face respectively. The follicular keratinocytes are seen to possess an amplified quantity of the desmosome as well as the tonofilaments due to which the ductal hyper cornification is evident when observed at the ultra-structural level ${ }^{13}$. The lesions of acne are mainly divided into two broad types either non-inflammatory lesions or inflammatory lesions ${ }^{14}$. Open (blackheads) or closed (whiteheads) comedones are mainly included in the non-inflammatory lesions ${ }^{14}$. While the Papules, pustules, and nodules/nodulocystic lesions are mainly classified as the inflammatory lesions with Computed Tomography (CT) to the dermal penetration of that inflammation's location and the degree of its severity ${ }^{14}$.

There has always been an active research in the pathology of the AV due to the high incidence in the population as well as its huge psychological influence that it has over the huge count of the population but yet the case of the pathogenesis of $\mathrm{AV}$ is still under multidimensional investigation since the last century ${ }^{15}$. AV is a uniform dermal disease with multifactorial etiology mainly characterized by the increase in sebum production, follicular hyperkeratinization, the colonization of the Propionibacterium acnes, and the inflammatory mediators released at the adjacent follicles of the dermis ${ }^{16}$.

Seborrhea is generally allied with acne. Irrespective of whether seborrhea is unswervingly interrelated with the development of acne lesions, seborrhea itself is exceedingly unpleasant for acne victims ${ }^{17}$. There is a direct correlation between the increased sebum production levels and the severity and occurrence of acne lesions hence for this motive; it is an imperative factor that should be taken into contemplation when taken the case of Acne Vulgaris Patients ${ }^{18}$. An inflammatory tissue response of the Pilosebaceous Unit (PSU) involving the release of pro-inflammatory cytokines including interleukin (IL)-I $\alpha$, IL-I $\beta$ and tumor necrosis factor- $\boldsymbol{\alpha}^{19}$. As well as proinflammatory mediators, such as leukotrienes and prostaglandins are propagated by the increased sebum production in Acne ${ }^{\mathrm{I} 9}$. Out of the entire natural microflora that resides the 
derm, only those bacteria specifically are pathogenic which in particular colonize the follicular duct and proliferate ${ }^{20}$. Propionibacteria, coagulase-negative staphylococci, and yeasts of the species Malassezia are the three species of microorganisms which therefore can be allied with the progress of acne lesions ${ }^{21}$. Keratinocytes, monocytes/macrophages, Langerhans cells, $\mathrm{T}$ and $\mathrm{B}$ lymphocytes, mast cells and endothelial cells have the TLRs, and these recognition receptors, recognize pathogen associated molecular patterns (PAMPs) ${ }^{22}$. On macrophages neighboring pilosebaceous follicles in histological samples of acne lesions, the occurrence of TLR-2 has been authenticated ${ }^{23}$.

It's been decades ever since the research is carried out on the relation between diet and $a^{2} e^{24}$. As associated with the non-smokers, there is substantiation that smokers are insulin resistant and hyperinsulinaemic as proved by the research ${ }^{25}$. Different physiological imbalances, for instance, hyper-insulinemia, dyslipidemia and extravagant adrenal androgen retort to Adrenocorticotrophic hormone (ACTH) have been witnessed in macho cigarette smokers. Significantly in the reported observations, the reaction of I7hydroxyprogesterone,Dehydroepiandrosterone (DHEAS) and androstenedione to ACTH was much complex in smokers compared to the non-smokers ${ }^{19}$. This DHEAS response to ACTH was a momentous element of insulin and therefore, smoking may barricade the adrenal 2I-hydroxylase occasioning in an escalation in the manufacture of adrenal androgens, which subsidize to the insulin confrontation in smokers as proposed. Despite the fact that the protagonist of smoking as a provoking factor in acne is still notorious, its marked role in hidradenitis suppurative (acne inversa) is well encouraged ${ }^{26}$. Acne is neither a fatal nor systemic disorder, yet its psychological effects are enormous. The objective of this study was to determine the prevalence of $A V$, its impact on individual's mental health and self-esteem.

\section{Methodology}

A cross-sectional, survey based study was conducted from February 2016 to October 2016. The sample was typically based on the Pakistani populace selected from various universities and school of Karachi. A total of 500 subjects via purposive sampling between I2 to 26 years of age were recruited. While all those with withheld informed consents were excluded from the study sample. A structured questionnaire with closed-ended questions was used for data collection. The questionnaire was classified into different sections concerning the demographic characteristics, skin type, complexion were inquired while the lifestyle factors like smoking, drinking habits and other factors leading to AV or associated stress were also interrogated. Data was collected after receiving the informed consents from the study population. The collected data was entered and analysed through SPSS Version I6. Chi-square test was used to determine the association between the AV outbreak and its impacts, where $\mathrm{p}$ value $<0.005$ was considered significant.

\section{Results}

The study population consisted of 500 patients, between the ages of $12-26$ years, where AV was found to be more prevalent in males $(52.4 \%)$ than in females. 
Table I: Represents the demographic characteristics of the study population

\begin{tabular}{|c|c|c|}
\hline Variables & Sub-categories & $\mathrm{n}(\%)$ \\
\hline \multirow[t]{2}{*}{ Gender distribution of $\mathrm{AV}$} & Male & $262(52.4)$ \\
\hline & Female & $238(47.6)$ \\
\hline \multirow[t]{3}{*}{ Kinds of AV } & Blackheads and whiteheac & $\mathrm{I} 40(28)$ \\
\hline & Papules and pustules & $\operatorname{IIO}(22)$ \\
\hline & Nodules and cysts & $250(50)$ \\
\hline \multirow[t]{2}{*}{ Age (Years) } & & Mean $\pm S D$ \\
\hline & & $19.5 \pm 3.60$ \\
\hline
\end{tabular}

${ }^{*} \mathrm{AV}=$ Acne Vulgaris, $(\mathrm{n}=500)$

Table 2: Represents the association of AV with different study parameters.

\begin{tabular}{lll}
\hline & Acne Vulgaris n (\%) & p-value \\
\cline { 2 - 3 } Declined Self-Confidence & $399(79.8 \%)$ & 0.197 \\
\cline { 2 - 3 } Declined Social Interest & $435(87 \%)$ & 0.001 \\
\cline { 2 - 3 } Dry Skin & $360(72 \%)$ & 0.18 \\
Oily Skin & $410(82 \%)$ & 0.000 \\
Skin Complexion & $370(74 \%)$ & 0.003 \\
Smoking & $410(82 \%)$ & 0.005 \\
Stress & $455(91 \%)$ & 0.000 \\
\hline
\end{tabular}

*p-value $<0.05$ was considered significant

It was evident that the sudden AV breakout lowers down the self-confidence and holds a negative impact on their confidence level of the individual. However, according to our results, there was no significant association found between the two variables ( $p=0.197)$. AV suffering youth of Karachi also have trouble with their social gatherings and end up cancelling numerous events due to this distressing outbreak ( $\mathrm{p}<$ 0.00I). The patients reported the outbreak of AV in forms of pastules, cysts and nodules which left scars on their faces, resulting in increase of stress in patients.

It was also observed that difference of skin types is associated with AV breakouts $(p<0.000)$ with the oily skin reported to be most debilitating in majority of the AV patients $(82 \%)$. The occurrence of different types of breakouts on patients face (mainly) contributed exacerbating stress in the suffering population. Stress was another factor which was reported in the study to instigate AV breakouts in patients which is highly irritating and distressful for them $(p<0.000)$. While smoking was also found as a strong trigger for the exacerbation of AV.

\section{Discussion}

$\mathrm{AV}$, a disease of the pilosebaceous units, is chronic and inflammatory ${ }^{27}$. Pilosebaceous units are most densely distributed in the face, neck, upper chest, shoulders and back in the acne vulgaris which leads to the outbreaks accordingly which are different in different subjects $^{28}$. Classically irresolute in its progression, AV is unpredictable due to its diversity of factors which aggravates it. It is medicinally recompensing to recognize and categorize the fretful prompts and provoking dynamics of $\mathrm{AV}$, in order to properly treat them and get a fruitful result ${ }^{29}$. In previous studies depression, anxiety and forlorn 
thoughts are more common among the acne patients $^{29}$. The dietary patterns are also considered as one of most influencing factors in the pathophysiology of acne, these nutrients have also been linked to human intellect, performance and sentiments ${ }^{30}$.

Similar research was conducted the same year in Bangladesh which also supports the point along with the Pakistani study of 2009 which is also consistent with previous findings that diet plays an immense role in $\mathrm{AV}^{3 \mathrm{I}}$. Even though gender demarcations have been reasonably highlighted in the past researches ${ }^{31}$, nevertheless in our study there was a high prevalence of $\mathrm{AV}$ reported in males $52.4 \%$ while $47.6 \%$ females in the sample respectively (Table I). Consistent with our findings, according to a study conducted in Malaysia male students were purportedly more temperately severe acne sufferers as paralleled to female students ${ }^{32}$. This is due to the fact that males have greasier skin owing to their androgen levels which are remarkably augmented.

AV manifestations are of various kinds consisting of cysts, nodules, whiteheads, and black heads ${ }^{12}$ and in our study the population of youth largely reported cysts and pastules which reportedly do leave offensive scars in more than half of the stated population. Due to lesions and scars, the AV patients perceive themselves as ugly and as a result undergo gigantic psychological problems mostly in relation to their self-esteem and confidence ${ }^{33}$. Some examiners consider AV as a biopsychosocial skin disorder. Various patients of AV had reported different years of sufferings ${ }^{34}$. According to our study, the adolescents who recently had an outbreak of acne, had lesser years of incidence as compared to the ones who were in their twenties. Similarly, a study concluded about the incidence of $\mathrm{AV}$, increased incidence of acne was reported as age increased, particularly in ages I4.I-I6 years old $^{12}$. According to an Australian training, the inclusive dominance of acne was 36.1\% whereas in UK, by Leeds Acne Grading Scale, the pervasiveness of acne in teenagers was reported to be $50 \%{ }^{35}$.

Due to varying breakout places, there is immense trouble in confidence building among the acne patients, especially with facial acne. Around $28 \%$ of the population suffering from AV reported about having non-inflammatory comedones whereas $22 \%$ complained about having inflammatory cysts (Table I). The important aspect of this result is concluding that $45.6 \%$ of the acne patients reported about having many manifestations at the same time which is indeed very distressing and excruciating as well. The most recurrent lesions in the study conducted in Japan were comedones which were concomitant with superior damage (itch, painful skin) accompanied by cysts and nodules and it was found similar in Japanese juveniles ${ }^{36}$.

In our current study, the manifestations of AV there is reportedly cancellation of social gatherings observed among the acne patients (Table 2). The emotional state of awkwardness and self-esteem concerns lead to self-consciousness and a diminution of selfpossession $^{37}$.

According to our study, smoking has a strong effect on the AV exacerbation and leads to profound stress among the affected. It is apparent through the study results that AV has a major impact on the subject's mental health and in turn affecting the quality of life of the sufferers. That is declined self-esteem and confidence among these individuals lead to depressive symptoms having a profound effect on their everyday life. 


\section{Conclusion}

Regardless of being the most prevalent common dermal condition, AV and its associated psychological impacts had been neglected worldwide. This under-rated public health dilemma may cause various psychosocial concerns such as diminished confidence, selfesteem, social rejections and serious mental health threats. Among those affected individuals. Awareness and education about this common life problem during young age can ensure a better quality of life and well-being.

\section{Conflicts of Interest}

None.

\section{Acknowledgement}

The authors are thankful to the entire team involved in this study and we appreciate their support throughout the study.

\section{Funding}

None.

\section{References}

I. Behnam B, Taheri R, Ghorbani R, Allameh P. Psychological impairments in the patients with acne. Indian J Dermatol. 20I3; 58(I): 26-29.

2. Mallon E, Newton JN, Klassen A, Stewart-Brown SL, Ryan TJ, Finlay AY. The quality of life in acne: A comparison with general medical conditions using generic questionnaires. Br J Dermatol. I999; I40(4):672-676.

3. Mosam A, Vawda NB, Gordhan AH, Nkwanyana N, Aboobaker J. Quality of life issues for South Africans with acne vulgaris. Clin Exp Dermatol. 2005;30(I):6-9.
4. Magin PJ, Pond CD, Smith WT, Goode SM. Acne's relationship with psychiatric and psychological morbidity: Results of a school-based cohort study of adolescents. J Eur Acad Dermatol Venereol. 2010; 24(I):58-64.

5. Stern RS. The prevalence of acne on the basis of physical examination. J Am Acad Dermatol. I992; 26(6): 93I- 935.

6. Rossen $\mathrm{MH}$, Roed-Petersen J. Acne vulgaris. Ugeskr Laeger.I993;I55(II): 775- 778

7. Dawson AL, Dellavalle RP. Acne vulgaris. BMJ. 2013;346: 30-33

8. Hsieh MF, Chen $\mathrm{CH}$. Delivery of pharmaceutical agents to treat acne vulgaris: current status and perspectives. J Med Biol Eng. 20I I;32(4):2I 5-24.

9. Jappe UT. Pathological mechanisms of acne with special emphasis on Propionibacterium acnes and related therapy. Acta Derm Venereol. 2003;83(4): 24I-248

I0. Ritvo E, Del Rosso JQ, Stillman MA, La Riche C. Psychosocial judgements and perceptions of adolescents with acne vulgaris: A blinded, controlled comparison of adult and peer evaluations. Bio Psycho Social medicine. 20I I;5(I):I I.

II. Gupta MA, Gupta AK. Depression and suicidal ideation in dermatology patients with acne, alopecia areata, atopic dermatitis and psoriasis. Br J Dermatol. I998; I39(5):846 - 850.

I2. Williams HC, Dellavalle RP, Garner S. Acne vulgaris. The Lancet. 2012;379(98I3):36I-372.

I3. Mancini AJ. Incidence, prevalence, and pathophysiology of acne. Adv Stud Med 2008, 8(4):I00-I05 
I4. Hentsch B, Schwarz S, inventors; G2M Cancer Drugs AG, assignee. Use of valproic acid for the topical treatment of mild to moderate acne vulgaris. United States patent application US I2/295,359. 2009.

15. Zouboulis CC, Eady A, Philpott M, Goldsmith LA, Orfanos C, Cunliffe WC, Rosenfield R. What is the pathogenesis of acne?. Exp Dermatol. 2005; I4(2):I43I52

I6. Vora S, Ovhal A, Jerajani H, Nair N, Chakrabortty A. Correlation of facial sebum to serum insulin-like growth factor-I in patients with acne. Br J Dermatol. 2008;I59(4):990-99I.

I7. Wertz PW, Michniak BB. Sebum. In Cosmeceuticals. Eds. Dekker M: New York, NY, USA, 2000; Volume 23, pp. $45-56$

I8. Ingham E, Eady EA, Goodwin CE, Cove JH, Cunliffe WJ. Pro-inflammatory levels of interleukin-Ialpha-like bioactivity are present in the majority of open comedones in Acne vulgaris. J Invest Dermatol. I992; 98(6): 895-901.

19. Bourne S, Jacobs A. Observations on acne, seborrhoea, and obesity. British medical journal. I956;I(4978): I268-I270.

20. Kumar B, Pathak R, Mary PB, Jha D, Sardana K, Gautam HK. New insights into acne pathogenesis: Exploring the role of acne-associated microbial populations. Dermatol Sin. 2016; 34(2):67-73.

2I. Marples RR, McGinley KJ. Corynebacterium acnes and other anaerobic diphtheroids from human skin. J Med Microbiol. I974;7(3):349-358.

22. Holland KT. Microbiology of acne. In: Cunliffe WJ, editor. Acne. London: Martin Dunitz; I989. p. 178-210.
23. Bialecka A, Mak M, Biedron R, Bobek M, Kasprowicz A, Marcinkiewicz J. Different pro-inflammatory and immunogenic potentials of Propionibacterium acnes and Staphylococcus epidermidis: implications for chronic inflammatory acne. Arch Immunol Ther Exp (Warsz). 2005;53(I):79-85.

24. Jalian HR, Liu PT, Kanchanapoomi M, Phan JN, Legaspi AJ, Kim J. All-trans retinoic acid shifts Propionibacterium acnes-induced matrix degradation expression profile toward matrix preservation in human monocytes. J Invest Dermatol. 2008; I28(I2):27772782.

25. Cordain L. Implications for the role of diet in acne. In Seminars in cutaneous medicine and surgery: WB Saunders. 2005; Vol. 24, No. 2, pp. 84-9I.

26. Kaymak Y, Adisen E, Ilter N, Bideci A, Gurler D, Celik B. Dietary glycemic index and glucose, insulin, insulin-like growth factor-I, insulin-like growth factor binding protein 3 , and leptin levels in patients with acne. J Am Acad Dermatol. 2007; 57(5): 819-823.

27. Hautanen A, Adlercreutz $\mathrm{H}$. Hyperinsulinaemia, dyslipidaemia and exaggerated adrenal androgen response to adrenocorticotropin in male smokers. Diabetologia. I993: 36(I2): I275I28I.

28. Ghodsi SZ, Orawa H, Zouboulis CC. Prevalence, severity, and severity risk factors of acne in high school pupils: a community-based study. J Invest Dermatol. 2009; I29(9):2136-2I4I.

29. Capitanio B, Sinagra JL, Ottaviani M, Bordignon V, Amantea A, Picardo M. 
'Smoker's acne': a new clinical entity?. Br J Dermatol. 2007;157(5):1070-I07I.

30. Lorenz TH, Graham DT, Wolf S. The relation of life stress and emotions to human sebum secretion and to the mechanism of acne vulgaris. J Lab Clin Med. I953;4I(I):I I-28.

3I. Snigdha KS, Zakaria AS, Bhuiyan MS, Islam MT, Islam M, Rahman S, Haque AR, Rahman MA. Patient perception on precipitating or aggravating factors for acne. Bangladesh Med J. 20I6; 45(I):3I35.

32. Layton AM. Disorders of the sebaceous glands. In: Burns T, Breathnach S, Cox N, Griffiths C, editors. Rook's textbook of dermatology, 8th edition. Oxford: Blackwell Science; 20I0. pp. I820-I822.

33. Stalder JF, Tennstedt D, Deleuran M, Fabbrocini G, De Lucas R, Haftek M, Taieb C, Coustou D, Mandeau A, Fabre B, Hernandez-Pigeon H. Fragility of epidermis and its consequence in dermatology. J Euro A Derma Venereology. 20I4;28(54):I-8.

34. Noorbala MT, Mozaffary B, Noorbala M. Prevalence of acne and its impact on the quality of life in high school-aged adolescents in Yazd, Iran. J Pak Assoc Dermatology. 2016;23(2):168-I72.

35. Smithard A, Glazebrook C, Williams HC. Acne prevalence, knowledge about acne and psychological morbidity in mid adolescence: A community base study. $\mathrm{Br}$ J Dermatol 200I; I45(2):274-279.

36. Hayashi N, Higaki Y, Kawamoto K, Kamo T, Shimizu S, Kawashima M. A cross-sec-23. tional analysis of quality of life in Japanese acne patients using the Japanese version of Skindex -I6. J Dermatol. 2004;3I(I2):97I-976.

37. Gollnick HP, Zouboulis CC. Not all acne is acne vulgaris. Dtsch Arztebl Int. 20I4; I II(I7):30I-3I2. 